\title{
Potentiation of immunological tolerance induction in adult mice by co-administration of pooled normal IgG and oral tolerogens: a potential therapeutic approach for autoimmune diseases
}

\author{
José Mengel ${ }^{* 1}$, Patrícia Fávaro, André Meyer, Vinícius Motta, \\ Raquel de Alencar, Edilberto Postól, Fabíola Cardillo ${ }^{1}$
}

Department of Immunology, Institute for Biomedical Sciences IV, University of São Paulo, Av. Prof. Lineu Prestes 1730, CEP 05508-900, São Paulo

Received 15 May 2004; accepted 26 October 2004

\begin{abstract}
Summary Oral tolerance can be defined as the inability of an adult animal to produce specific antibodies or cellular immune responses upon conventional immunization, after oral antigenic administration. Recently, the oral administration of antigens has gained renewed interest because of the possibility of inducing tolerance in nonimmunized adult animals and, consequently, opening up the theoretical possibility of preventing or treating diseases caused by malfunction of the immune system. This strategy has been proven to be useful in the prevention of allergic and autoimmune diseases in rodents, as well as in the amelioration of certain autoimmune diseases in humans. Although there is experimental and clinical evidence for the usefulness of oral tolerance in medical practice, the mechanisms responsible for this phenomenon are still poorly understood, and the results obtained are not always satisfactory. Herein, we show that the thymus is required for the induction and maintenance of oral tolerance, providing evidence that it is not a pure form of clonal deletion-based peripheral tolerance. Oral tolerance could therefore depend on the formation and release to the periphery of regulatory T cells, such as $\gamma \delta$ or $\alpha \beta$ T cells, by the thymus. This finding may have profound implications for the treatment of autoimmune diseases, since most of them are associated with thymic hypofunction. On the other hand, due to so far unknown mechanisms, the intraperitoneal co-administration of normal lgG to mice orally treated with tolerogen leads to a sustained and intense immunological tolerance, both in euthymic and thymectomized mice, including those of the lupus erythematosus-prone NZB $\times$ NZW lineage. This approach for inducing and maintaining tolerance in thymus-deficient conditions is discussed and put forth herein as a new evidence-based proposition for the therapy of autoimmune diseases.
\end{abstract} (c) 2004 Elsevier Ltd. All rights reserved.

\footnotetext{
* Corresponding author. Tel./fax: +55 713560101x270.

E-mail address: jomengel@cpqgm.fiocruz.br, jomengel@terra.com.br (José Mengel).

1 Present address: Oswaldo Cruz Foundation, Gonçalo Moniz Research Center, R. Waldemar Falcão 121, CEP 40295-001 Salvador, Bahia, Brazil. Cellular Immunology, Autoimmunity and Experimental Chagas Disease Laboratory.
} 


\section{Oral tolerance and autoimmune diseases}

The oral administration of antigens has been used to the ameliorate autoimmune disorders in rodents and humans in order to re-establish tolerance to self components [1]. Clinical trials have shown that human autoimmune diseases such as multiple sclerosis, uveitis, and arthritis can be treated with relative success, using this approach [2]. Most importantly, such trials reveal the absence of major side effects [1]. However, the overall results of many clinical trials have not been as promising as originally predicted [3]. The discrepancy between the excellent results in the prevention of autoimmune diseases in animal models and the treatment of human autoimmune pathologies probably reflects the influence of several factors, including those discussed below:

(a) Contrasting to the experimental induction of oral tolerance, which is usually carried out in normal animals, in the treatment of autoimmune pathologies in humans it is attempted to re-establish tolerance when the immune system is already commited to an autoimmune state and/or is otherwise malfunctioning [4].

(b) The schedule of antigen administration and doses are well established for rodents, but not for humans [1].

(c) The mechanisms by which oral tolerance is induced and maintained in humans are still unclear [1].

(d) The age of the subject at the time of oral tolerogenic treatment [5] may be comparatively higher in human patients than in experimental animals.

(e) The nature of the antigens used to induce oral tolerance in experimental animals and human patients may differ [6].

In addition, autoimmune diseases may have distinct pathological mechanisms, and many of them may not be suitable to treatment by the induction of oral tolerance.

Currently, the oral administration of antigens is a promising way of treating autoimmune diseases. However, new insights into the mechanisms responsible for oral tolerization and the development of new protocols or the association of protocols are required so as to improve the clinical results.

In this article, we will discuss the development of the immune system, the interplay among lymphocytes and the results that show an unexpected role of the thymus in the acquisition and mainte- nance of oral tolerance, through the release of special thymic emigrant cells. Finally, we propose an association of two protocols for the treatment of autoimmune diseases.

\section{T Lymphocyte deletion}

Clonally distributed receptors known as $\mathrm{T}$ cell receptors (TCRs) and immunoglobulins (Igs) are expressed on T and B cells, respectively [7]. TCRs and Igs are essential for the development of mature $T$ and $B$ cells since the lack of their expression results in the absence of mature $\mathrm{T}$ or B lymphocytes [8]. The expression of MHC molecules on thymic epithelial cells is also crucial for the maturation/differentiation of $\mathrm{T}$ cells since animals unable to express MHC molecules do not develop mature $\mathrm{T}$ lymphocytes [9]. Thus the expression of TCRs and of MHC molecules on thymic stromal cells are required for the appearance of mature T cells. The TCR recognizes peptides bound to MHC molecules [10]. A strong interaction between an immature $\mathrm{T}$ cell and a MHC-peptidepresenting cell in the thymus results in the death of that particular $\mathrm{T}$ cell with a given specificity (negative selection). A weak interaction rescues immature $T$ cells from apoptosis and sustains the progression of the maturation/differentiation process of a particular $T$ cell that leaves the thymus to peripheral lymphoid tissues (positive selection). A third situation and, probably the most frequent, involves a $T$ cell carrying a particular rearranged TCR which prevents any possible interaction with the array of MHC-peptides expressed by the thymic stromal cells at a given time. In such a case, the thymocytes perish by neglect [11]. The end result of the selection process is the shaping of a $T$ cell repertoire by the elimination of $T$ cells that have high or no avidity for a given combination of MHC-peptide-presenting cells in the thymus. This phenomenon enhances the maturation/differentiation of peptide-MHC-interactive $T$ cells with a low/intermediate avidity for MHC-peptide-expressing thymic cells [11]. This model implies that every mature $\mathrm{T}$ cell in peripheral lymphoid organs was positively selected in the thymus by a given array of MHC-peptides (probably of self nature) in the context of a given MHC haplotype [12]. Positive selection is an intricate process [13] in that a given TCR may be positively selected by a balance of a given array of quantitatively or qualitatively different peptides or a given peptide may positively select a 
repertoire of certain complexity [14]. These observations suggest that most peripheral $T$ cells are autoreactive to some extent, thus implicating autoreactivity in the existence and survival of $T$ cells in peripheral lymphoid organs [15]. This conclusion does not necessarily imply the existence of suppressor and/or regulatory $\mathrm{T}$ cells, as any potentially deleterious autoimmune responses could still be controlled by increasing the ratio of the peripheral negative selection of autoaggressive $\mathrm{T}$ cells. This would be achieved by increasing the overall avidity between $T$ cells and antigen-presenting cells under microenvironmental conditions with supra optimal antigen presentation [13]. A high concentration of self or non-self antigens would, therefore, cause central and peripheral deletion of $\mathrm{T}$ cell-reactive clones, thus resulting in tolerance [16]. Indeed, there is evidence that the oral administration of high concentrations of antigens may lead to partial deletion of responder T cells[17]. However, we show herein that the transfer of splenic cells from orally tolerant BALB/C mice to athymic BALB/C nu/nu recipient mice produces a transient state of tolerance that can be interrupted by successive antigenic boosters. The period required for the recipient mice to recover the immune response varied from 30 days (donor mice tolerized with low doses of antigens) to 5 months (donor mice tolerized with high doses of antigen) after transfer. Control euthymic mice that were made tolerant by gavaging with high- or low-doses of ovalbumin (OVA) remained tolerant for at least 7 months (Fig. 1). These findings argue against the hypothesis that clonal deletion is the sole mechanism responsible for oral tolerance. They also suggest that high doses of antigens could determine a more stable state of oral tolerance.

\section{The thymus is required for the establishment of oral tolerance}

The long duration of oral tolerance seen in euthymic mice is particularly interesting since thymic emigrant $T$ cells are continuously released from the murine thymus at a rate of approximately one million cells per day [18]. Since these new T cells have not undergone tolerization, it would be reasonable to assume that they would produce normal immune responses upon conventional immunization. Yet, in orally tolerized mice, tolerance persists, as shown herein, for at least 7 months after gavage, a period in which about 200 million new $\mathrm{T}$ cells were introduced in the periphery. This

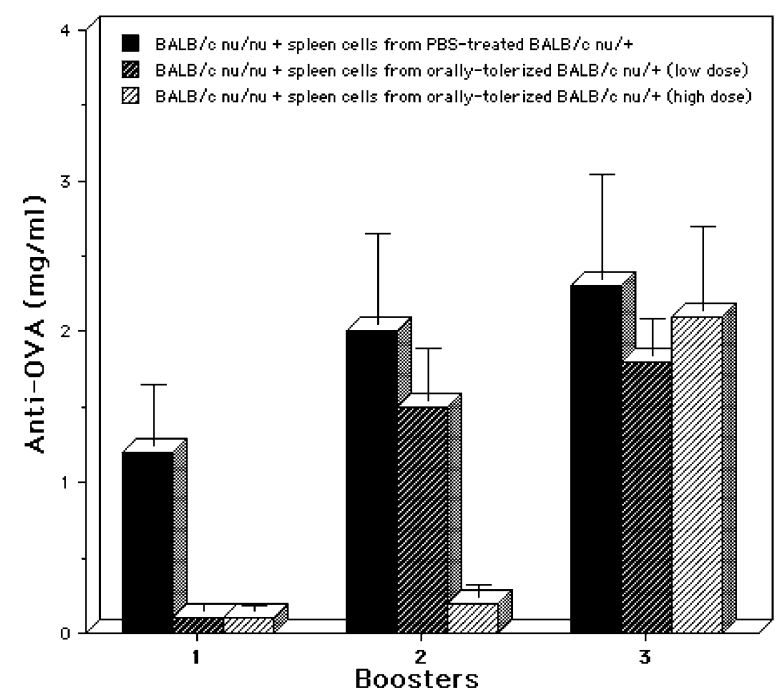

Figure $1 \mathrm{BALB} / \mathrm{c}$ nu/nu mice reconstituted with spleen cells from orally tolerant $B A L B / C$ nu/ + mice are unable to sustain the state of tolerance. BALB/c nu/nu mice were reconstituted with $5 \times 10^{7}$ spleen cells from $B A L B / c$ nu/+ mice submitted to three consecutive gavages of PBS or 5 $\mathrm{mg}$ (low dose) or $20 \mathrm{mg}$ (high dose) of OVA in PBS. Reconstituted BALB/c nu/nu mice were immunized (i.p.) with $100 \mu \mathrm{g}$ of OVA in alumen ( $1 \mathrm{mg} /$ animal) on the day of the transfer (booster 1 ) and with $100 \mu \mathrm{g}$ of soluble OVA on day +14 (booster 2) and +135 (booster 3). Sera were collected 15 days after each booster and assayed for the antibodies (all isotypes) specific to OVA using a quantitative ELISA. The concentration $(\mathrm{mg} / \mathrm{ml})$ of antibodies to OVA in each serum sample was calculated from a standard curve generated with known amounts of OVAspecific, affinity-purified antibodies from OVA-hyperimmunized $\mathrm{BALB} / \mathrm{c}$ nu/+ mice. The columns represent the mean $\pm \mathrm{SD}(n=4-6$ mice $)$. BALB/c nu/+ mice orallytolerized with low or high amounts of OVA remained tolerant for at least 7 months as their total amount of OVA-specific antibodies was always below $0.3 \mathrm{mg} / \mathrm{ml}$ during this period. " $p \leqslant 0.01$ (Mann-Whitney).

observation suggests that other mechanisms, besides clonal deletion, are operating to maintain the state of oral tolerance.

To evaluate the role of the thymus in the induction and maintenance of oral tolerance, one experiment was performed. Fig. 2 shows that DBA/2 mice thymectomized 2 months before gavage with high doses of OVA developed tolerance at the level of specific antibody production. However, unlike euthymic mice, and similarly to athymic nu/nu mice, thymectomized mice were unable to sustain oral tolerance for a long period of time. In another series of experiments, thymectomized F1 (C57BI/ $6 \times \mathrm{BALB} / \mathrm{c}$ ) mice underwent gavage with high (three gavages with $5 \mathrm{mg} /$ gavage) or low doses (three gavages with $0.5 \mathrm{mg} /$ gavage) of OVA. 


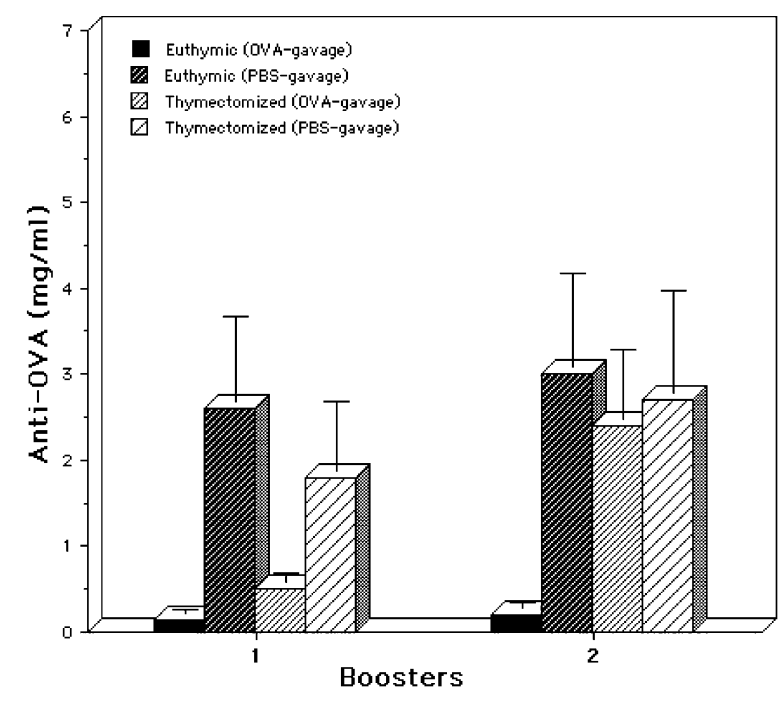

Figure 2 Thymectomized DBA/2 mice do not sustain oral-induced tolerance for long periods of time. DBA/2 mice underwent one gavage of PBS or $20 \mathrm{mg}$ of ovalbumin 2 months after thymectomy. The mice were then immunized (i.p.) with $100 \mu \mathrm{g}$ of OVA in alumen (1 $\mathrm{mg}$ /animal) 7 days after gavage and with $100 \mu \mathrm{g}$ of soluble OVA on day +21 (booster 1 ) and +35 (booster 2 ). Sera were collected 15 days after each booster and assayed for the amount of antibodies (all isotypes) specific to OVA using a quantitative ELISA. Control groups included aged-matched euthymic and thymectomized DBA/2 mice submitted to gavage with PBS or OVA and immunized as described above. The columns represent the mean \pm SD $(n=5-8) .{ }^{*} p \leqslant 0.01$ (Mann-Whitney).

Control imunized mice in these experiments produced $3.1 \pm 0.5 \mathrm{mg} / \mathrm{ml}$ of anti-OVA specific antibodies in the secondary immune response. Mice in which oral tolerance was induced with a low dose of OVA were poorly tolerized $(1.9 \pm 0.4 \mathrm{mg} / \mathrm{ml}$ of anti-OVA specific antibodies in the secondary immune response) compared to those tolerized with a high OVA dose $(0.5 \pm 0.1 \mathrm{mg} / \mathrm{ml}$ of anti-OVA specific antibodies in the secondary immune response). Tolerance in both groups was not sustained for longer than 5 months (data not shown). These results suggest that the thymus is an important organ either in the induction (low antigenic doses) or in the maintenance (low and high antigen doses) of oral tolerance.

Recent studies have suggested that the thymus may have a major role in the normal immune system functioning in adult mammals. Thus normal thymic activity may maintain an output of "virgin" $T$ cells as well as minor $T$ cell subpopulations with important functional activities in adults. In this case, the thymus serves as an important source of regulatory $T$ cells in the early and late phases of ontogeny [19]. It has been seen that $C D 4^{+} C D 45 R^{\text {high }}$,
$\mathrm{CD}^{+} \mathrm{CD} 25^{+}, \mathrm{NK} 1.1^{+} \alpha \beta^{+}$and $\gamma \delta^{+} \mathrm{T}$ cells, which are among thymic emigrant $T$ cells, have regulatory functions either in the generation of memory or in the induction of tolerance [20-25].

\section{$\gamma \delta$ T cells as regulatory cells in the induction and maintenance of oral tolerance}

$\gamma \delta \mathrm{T}$ cells show distinct functional patterns and are involved either in the induction and maintenance of tolerance or in the upregulation of immune responses. $\alpha \beta^{+} \mathrm{CD}^{+} \mathrm{T}$ cells from $\gamma \delta \mathrm{T}$ cell-depleted mice show increased levels of IL-2 production and thymidine incorporation when cultured with syngeneic filler cells [26]. Hepatic $\gamma \delta$ T cells from mice made tolerant by the transfer of spleen cells from minor histocompatibility-mismatched mice induced tolerance in naive recipients [27]. $\gamma \delta \mathrm{T}$ cells can also down-regulate the helper activity of $\alpha \beta^{+} C D 4^{+} T$ cells by suppressing IgE production in vivo [28]. Splenic $\gamma \delta$ T cells from Trypanosoma cruzi-infected mice can block mixed lymphocyte reaction proliferation and the production of IFN- $\gamma$ by $\alpha \beta^{+}$T cells in vitro [29]. The latter $\gamma \delta$ T cell suppressor activity was recently shown to be thymus dependent [24]. In this model, nonspecific suppression of the antibody response could be reversed by in vivo $\gamma \delta$ T-cell depletion. Furthermore, we have demonstrated that $\gamma \delta \mathrm{T}$ cell-depleted mice are not susceptible to the induction of oral tolerance with OVA and that, once established, oral tolerance could be terminated by depleting $\gamma \delta$ T cells [30]. The latter results have been confirmed and extended in $\delta$ knockout mice [31]. In addition, insulin inhalation can delay or prevent diabetes in NOD mice, an effect mediated by $\gamma \delta \mathrm{T}$ cells[32]. Also, a positive regulatory influence of $\gamma \delta$ T cells on $\alpha \beta$ T cells has also been demonstrated [33].

$\gamma \delta \mathrm{T}$ cells of thymic origin are short-lived [34] and consist of $\mathrm{CD}^{+}, \mathrm{CD}_{28}^{+}, \mathrm{CD} 40$-ligand ${ }^{+}, \mathrm{Fas}^{+}$, $\mathrm{Fc} \gamma \mathrm{R}^{+}$cells [35]. In fact, we have detected low percentages of $\gamma \delta^{+} \mathrm{Fas}^{+}$cells after thymectomy $\left(6 \pm 2.8 \%\right.$ of Fas $^{+} \gamma \delta^{+} \mathrm{T}$ cells among splenic $\gamma \delta^{+} \mathrm{T}$ cells) and an increase in their levels after the injection of thymocytes into thymectomized mice $\left(14.8 \pm 4.7 \%\right.$ of Fas $^{+} \gamma \delta^{+}$T cells among splenic $\gamma \delta^{+}$ $T$ cells). In addition, it was recently described that a subpopulation of $\mathrm{V} \gamma 1^{+} \gamma \delta \mathrm{T}$ cells are able to kill activated macrophages via Fas-Fas-L interaction [36]. This study is of particular interest as it may contribute to the understanding of the mechanism by which a subset of $\gamma \delta$ T cells could control the 
activation of conventional $\alpha \beta^{+}$T cells, albeit in an indirect way by diminishing the numbers of potential activated antigen-presenting cells. Other studies support the idea that $\gamma \delta \mathrm{T}$ cells have, or acquire, different effector functions, depending on their interactions with the microenvironment [37]. The studies and results discussed herein strongly suggest the participation of the thymus in the induction and maintenance of oral tolerance in normal animals through positive selection of one or more $\mathrm{T}$ cell lineages.

\section{Immunoglobulins and oral tolerance}

Although B cells are not fundamental for the induction of tolerance [38], they may be important in the regulation of immune responses. For instance, B cells may work as regulatory cells in certain experimental autoimmune diseases [39] or in the maintenance of T cell anergy [40]. The mechanism by which $B$ cells exert these effects is not yet understood. However, a recent report has shown that animals which do not express the Fc gamma receptor because of a gene target mutation are highly susceptible to the induction of arthritis upon collagen immunization [41]. These results indicate that $\mathrm{Fc}$ receptors and immunoglobulins are involved in the regulation of immune responses, as previously suggested [42]. Indeed, the administration of large quantities of human immunoglobulins to patients with different types of autoimmune disease has been shown to improve their clinical condition [43]. Thus B cells, through their major product (immunoglobulins), could theoretically be important in the regulation of oral tolerance. In fact, euthymic $\mathrm{F} 1(\mathrm{C} 57 \mathrm{BL} / 6 \times \mathrm{BALB} / \mathrm{c})$ mice intraperitoneally (i.p.) injected with protein-A purified IgG from pooled normal mouse sera and subjected to oral tolerization with low doses of antigen become highly tolerant, indicating a potentiation of the classical protocol by the administration of normal immunoglobulins. The same type of experiment was done in young $\mathrm{F} 1(\mathrm{NZB} \times \mathrm{NZW})$ mice. These mice are totally resistant to the induction oral tolerance by the use of relatively low doses of antigen. However, the administration of pooled normal IgG (i.p.) and antigen by the oral route renders NZB $\times$ NZW mice completely tolerant at the level of the specific humoral response (Fig. 3). These results strongly suggest that the co-administration of pooled normal IgG potentiates the induction of oral tolerance in normal or autoimmune prone mice strains.

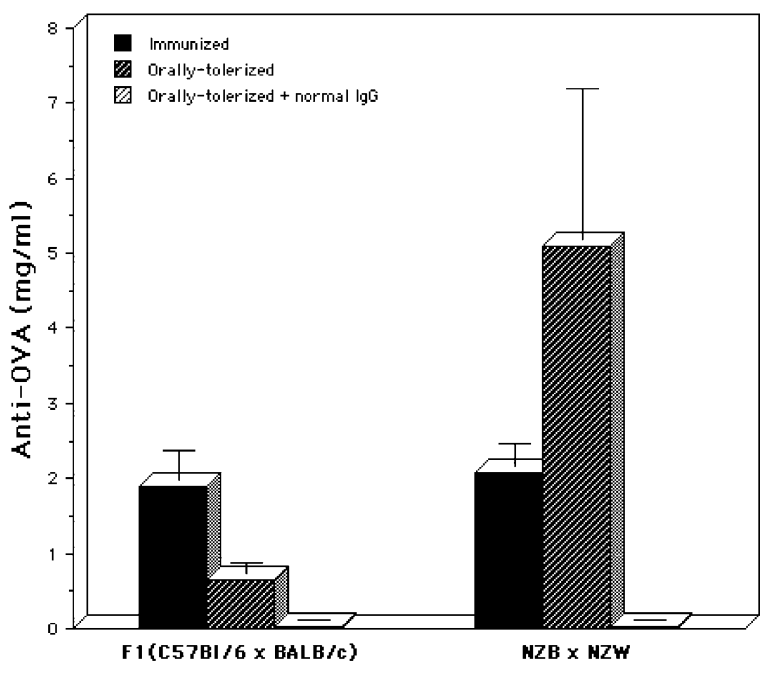

Figure 3 Purified normal mouse IgG potentiates the induction of oral tolerance in mice. Two-month-old $\mathrm{F} 1(\mathrm{C} 57 \mathrm{Bl} / 6 \times \mathrm{BALB} / \mathrm{C})$ or $\mathrm{F} 1(\mathrm{NZB} \times \mathrm{NZW})$ mice were either injected i.p. with $1 \mathrm{mg}$ of protein-A purified normal IgG from pooled sera or PBS every other day, starting 1 week before the initial gavage procedure and continuing for up to 15 days post-gavage (days $-7,-5$, $-3,-1,+1,+3,+5,+7,+9,+11,+13,+15)$. The mice also underwent to three gavages with PBS or $0.5 \mathrm{mg}$ or $2 \mathrm{mg}$ of OVA for $\mathrm{F} 1(\mathrm{C} 57 \mathrm{Bl} / 6 \times \mathrm{BALB} / \mathrm{C}) / \mathrm{F} 1(\mathrm{NZB} \times \mathrm{NZW})$ mice respectively, on days $0,+1$ and +2 . Mice were then immunized (i.p.) with $100 \mu \mathrm{g}$ of OVA in alumen $(1 \mathrm{mg} /$ animal) 7 days after the initial gavage and with $100 \mu \mathrm{g}$ of soluble OVA on day +14 . Sera were collected 14 days after the secondary immunization and specific antibodies to OVA quantified by ELISA (see Fig. 1). The columns represent the mean \pm SD $(n=4-7$ mice $)$.

\section{Lymphopenia and autoimmune diseases}

Autoimmune diseases are in general associated to T-cell lymphopenia [44]. Lymphopenia may be due to deficient thymic function and/or peripheral $T$ cell loss due to terminal differentiation, recruitment to inflammatory sites and death $[45,46]$. In addition, in many autoimmune diseases the thymic function is severely reduced, both in rodents and in human beings [47-50]. In fact, thymic hypofunction might be one of the causes of autoimmune diseases [44]. More importantly, as we discussed above, a functioning thymus is required for in the induction and/or maintenance of oral tolerance in normal animals. These observations might account for the modest results found in many clinical trials that use oral tolerance as a principle to reestablish self-tolerance. Therefore, therapies aiming at treating autoimmune diseases might consider the correction of $\mathrm{T}$ cell lymphopenia by means of restoring 
thymic function (production and/or export of regulatory $\mathrm{T}$ cells) or, alternatively, to be based in strategies for inducing peripheral tolerance that do not require normal thymic function. In Fig. 4 we show that either thymectomized F1(BALB/ $\mathrm{C} \times \mathrm{C} 57 \mathrm{Bl} / 6)$ or autoimmune prone thymectomized F1 $(N Z B \times N Z W)$ could be rendered extremely tolerant at the level of antibody production to low doses of antigen (OVA), administered by the oral route when polyclonal IgG was given i.p., concomitantly. Also, these thymectomized animals remained tolerant for more than 6 months (data not shown). These experiments show that the combination of the oral tolerance protocol with the co-administration of normal pooled IgG bypasses the requirement for a functional thymus

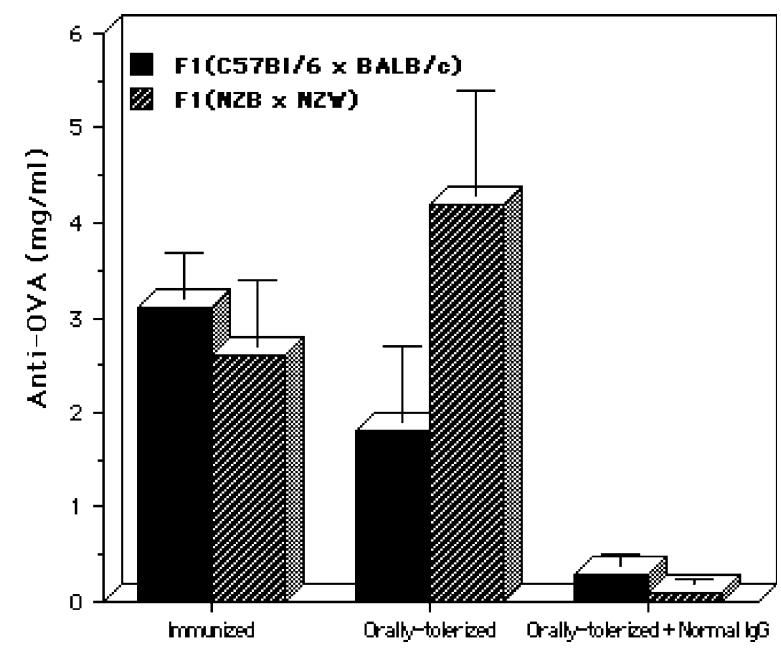

Figure 4 Oral tolerance induction to low doses of antigen is potentiated by coadministration of normal pooled IgG in thymectomized mice. Four-month-old thymectomized $\mathrm{F} 1(\mathrm{C} 57 \mathrm{Bl} / 6 \times \mathrm{BALB} / \mathrm{C})$ or $\mathrm{F} 1(\mathrm{NZB} \times \mathrm{NZW})$ mice were either injected i.p. with $1 \mathrm{mg}$ of protein-A purified normal IgG from pooled sera or PBS every other day, starting 1 week before the initial gavage procedure and continuing for up to 15 days post-gavage (days -7 , $-5,-3,-1,+1,+3,+5,+7,+9,+11,+13,+15)$. The mice also underwent to three gavages with $\mathrm{PBS}$ or $0.5 \mathrm{mg}$ or 2 $\mathrm{mg}$ of OVA for $\mathrm{F} 1(\mathrm{C} 57 \mathrm{Bl} / 6 \times \mathrm{BALB} / \mathrm{C}) / \mathrm{F} 1(\mathrm{NZB} \times \mathrm{NZW})$ mice respectively, on days $0,+1$ and +2 . Mice were then immunized (i.p.) with $100 \mu \mathrm{g}$ of OVA in alumen (1 $\mathrm{mg}$ /animal) 7 days after the initial gavage and with $100 \mu \mathrm{g}$ of soluble OVA on day +14 . Sera were collected 14 days after the secondary immunization and specific antibodies to OVA quantified by ELISA (see Fig. 1). Mice were thymectomized 2 months before the beginning of the experiments. The columns represent the mean \pm SD ( $n=5-9$ mice). All the protocols used in this study were approved by the Committee for Ethics in Animal Experimentation of the University of São Paulo. All protocols involved in this study are committed to promoting and ensuring the well being of animals. and therefore, might be of extremely importance in the treatment of some autoimmune diseases.

\section{Concluding remarks}

1. A functioning thymus seems to be crucial for the induction and/or maintenance of oral tolerance by exporting regulatory/suppressor cells in normal animals.

2. Thymic function is decreased in autoimmune diseases.

3. The induction of oral tolerance in normal or autoimmune prone strains of mice is extremely potentiated by the co-administration of pooled IgG from normal mice.

4. Oral tolerance to low doses of antigen can be induced and maintained in thymus-less animals, having normal or autoimmune genetic backgrounds, that received normal IgG. Therefore, the mechanism underlining this biological effect might be, purely, peripheral.

5. Treatments aiming the amelioration of autoimmune diseases could combine both protocols (oral tolerance and intravenously administration of Ig (IV-lg) as it may be more effective, without important predictable side effects.

\section{Acknowledgements}

This work was supported by Grants from CNPq and FAPESP (proc. 95/09379-2 and 97/6225-0) and by fellowships from CNPq (J.M.), FAPESP (P.B., A.M., V.M. and F.C.) and CAPES (R.A.). We thank Dr. Lain Pontes de Carvalho for critical reading of the manuscript.

\section{References}

[1] Faria AM, Weiner HL. Oral tolerance: mechanisms and therapeutic applications. Adv Immunol 1999;73:153-264.

[2] Weiner HL, Komagata Y. Oral tolerance and the treatment of rheumatoid arthritis. Springer Semin Immunopathol 1998;20(1-2):289-308.

[3] MacDonald TT. T cell immunity to oral allergens. Curr Opin Immunol 1998;10(6):620-7.

[4] Verdolin BA, et al. Systemic immunization of mature mice by the oral route. Braz J Med Biol Res 1993;26(7):725-34.

[5] Faria AM, et al. Decrease in susceptibility to oral tolerance induction and occurrence of oral immunization to ovalbumin in 20-38-week-old mice. The effect of interval 
between oral exposures and rate of antigen intake in the oral immunization. Immunology 1993;78(1):147-51.

[6] Weiner HL. Oral tolerance with copolymer 1 for the treatment of multiple sclerosis. Proc Natl Acad Sci USA 1999;96(7):3333-5.

[7] Tonegawa S. Antibody and T-cell receptors. Jama 1988;259(12):1845-7.

[8] Mombaerts $\mathrm{P}$, et al. Mutations in T-cell antigen receptor genes alpha and beta block thymocyte development at different stages. Nature 1992;360(6401):225-31.

[9] Zijlstra $M$, et al. Beta 2-microglobulin deficient mice lack CD4-8+ cytolytic T cells. Nature 1990;344(6268):742-6.

[10] Kisielow P, von Boehmer H. Negative and positive selection of immature thymocytes: timing and the role of the ligand for alpha beta $T$ cell receptor. Semin Immunol 1990;2(1):35-44.

[11] von Boehmer H, Teh HS, Kisielow P. The thymus selects the useful, neglects the useless and destroys the harmful. Immunol Today 1989;10(2):57-61.

[12] Ashton-Rickardt PG, Tonegawa S. A differential-avidity model for T-cell selection. Immunol Today 1994;15(8): 362-6.

[13] Williams 0 , et al. The agonist-antagonist balance in positive selection. Immunol Today 1997;18(3):121-6.

[14] Ignatowicz L, Kappler J, Marrack P. The repertoire of T cells shaped by a single $\mathrm{MHC} /$ peptide ligand. Cell 1996;84(4):521-9.

[15] Kirberg J, Berns A, von Boehmer H. Peripheral T cell survival requires continual ligation of the $T$ cell receptor to major histocompatibility complex encoded molecules. J Exp Med 1997;186(8):1269-75.

[16] Chen YH, Weiner HL. Dose-dependent activation and deletion of antigen-specific $T$ cells following oral tolerance. Ann N Y Acad Sci 1996;778:111-21.

[17] Chen $Y$, et al. Peripheral deletion of antigen-reactive $T$ cells in oral tolerance. Nature 1995;376(6536):177-80.

[18] Scollay RG, Butcher EC, Weissman IL. Thymus cell migration. Quantitative aspects of cellular traffic from the thymus to the periphery in mice. Eur J Immunol 1980;10(3): 210-8.

[19] Seddon B, Mason D. The third function of the thymus. Immunol Today 2000;21(2):95-9.

[20] Powrie F, Mason D. The MRC OX- 22+CD4+ T cells that help $B$ cells in secondary immune responses derive from naive precursors with the MRC OX-22+CD4+ phenotype. J Exp Med 1989;169(3):653-62.

[21] Bendelac A, et al. A subset of CD4+ thymocytes selected by MHC class I molecules. Science 1994;263(5154):1774-8.

[22] Itoh $M$, et al. Thymus and autoimmunity: production of CD25+CD4+ naturally anergic and suppressive $T$ cells as a key function of the thymus in maintaining immunologic self-tolerance. J Immunol 1999;162(9):5317-26.

[23] de Albuquerque DA, et al. The development of humoral immunological memory to a T-cell-dependent antigen requires thymic emigrant cells. Res Immunol 1994;145(3): 185-95.

[24] Cardillo F, Nomizo A, Mengel J. The role of the thymus in modulating gammadelta $T$ cell suppressor activity during experimental Trypanosoma cruzi infection. Int Immunol 1998;10(2):107-16.

[25] Azuara V, et al. A novel subset of adult gamma delta thymocytes that secretes a distinct pattern of cytokines and expresses a very restricted $T$ cell receptor repertoire. Eur J Immunol 1997;27(2):544-53.

[26] Kaufmann SH, Blum C, Yamamoto S. Crosstalk between alpha/beta $T$ cells and gamma/delta $T$ cells in vivo: activation of alpha/beta T-cell responses after gamma/delta T-cell modulation with the monoclonal antibody GL3. Proc Natl Acad Sci USA 1993;90(20): 9620-4.

[27] Gorczynski RM, et al. Gamma delta TCR+ hybridomas derived from mice preimmunized via the portal vein adoptively transfer increased skin allograft survival in vivo. J Immunol 1996;157(2):574-81.

[28] McMenamin C, et al. Gamma delta T cells down-regulate primary IgE responses in rats to inhaled soluble protein antigens. J Immunol 1995;154(9):4390-4.

[29] Cardillo F, et al. An age-related gamma delta $T$ cell suppressor activity correlates with the outcome of autoimmunity in experimental Trypanosoma cruzi infection. Eur J Immunol 1993;23(10):2597-605.

[30] Mengel J, et al. Anti-gamma delta T cell antibody blocks the induction and maintenance of oral tolerance to ovalbumin in mice. Immunol Lett 1995;48(2):97-102.

[31] Ke $Y$, et al. Gamma delta $T$ lymphocytes regulate the induction and maintenance of oral tolerance. J Immunol 1997;158(8):3610-8.

[32] Harrison LC, et al. Aerosol insulin induces regulatory CD8 gamma delta $T$ cells that prevent murine insulin-dependent diabetes. J Exp Med 1996;184(6):2167-74.

[33] Fujihashi K, et al. Function of alpha beta TCR+ and gamma delta TCR+ IELs for the gastrointestinal immune response. Int Rev Immunol 1994;11(1):1-14.

[34] Tough DF, Sprent J. Lifespan of gamma/delta T cells. J Exp Med 1998;187(3):357-65.

[35] Szczepanik M, Ptak W, Askenase PW. Role of interleukin-4 in downregulation of contact sensitivity by gammadelta $T$ cells from tolerized T-cell receptor alpha-/- mice. Immunology 1999;98(1):63-70.

[36] Dalton JE, et al. Fas-Fas ligand interactions are essential for the binding to and killing of activated macrophages by gammadelta T cells. J Immunol 2004;173(6): 3660-7.

[37] Ferrick DA, et al. Differential production of interferongamma and interleukin-4 in response to Th1- and Th2stimulating pathogens by gamma delta $\mathrm{T}$ cells in vivo. Nature 1995;373(6511):255-7.

[38] Phillips JA, et al. CD4+ T cell activation and tolerance induction in $B$ cell knockout mice. J Exp Med 1996;183(4):1339-44.

[39] Wolf SD, et al. Experimental autoimmune encephalomyelitis induction in genetically $B$ cell-deficient mice. J Exp Med 1996;184(6):2271-8.

[40] Aroeira LS, et al. Anti-Vbeta8 antibodies induce and maintain staphylococcal enterotoxin B-triggered Vbeta8+ T cell anergy. Eur J Immunol 1999;29(2):437-45.

[41] Yuasa $T$, et al. Deletion of fcgamma receptor IIB renders $\mathrm{H}-2$ (b) mice susceptible to collagen-induced arthritis. J Exp Med 1999;189(1):187-94.

[42] Whitmer KJ, Romball CG, Weigle WO. Induction of tolerance to human gamma-globulin in FCR gamma- and Fc gammaRIl-deficient mice. J Immunol 1997;159(2): 644-9.

[43] Good RA, Lorenz E. Historic aspects of intravenous immunoglobulin therapy. Cancer 1991;68(6 Suppl):1415-21.

[44] Hori S, Takahashi T, Sakaguchi S. Control of autoimmunity by naturally arising regulatory CD4+ T cells. Adv Immunol 2003;81:331-71.

[45] King C, et al. Homeostatic expansion of $\mathrm{T}$ cells during immune insufficiency generates autoimmunity. Cell 2004;117(2):265-77.

[46] Brenchley JM, et al. CD4+ T cell depletion during all stages of HIV disease occurs predominantly in the gastrointestinal tract. J Exp Med 2004;200(6):749-59. 
[47] Hug A, et al. Thymic export function and T cell homeostasis in patients with relapsing remitting multiple sclerosis. J Immunol 2003;171(1):432-7.

[48] Ponchel F, et al. Dysregulated lymphocyte proliferation and differentiation in patients with rheumatoid arthritis. Blood 2002;100(13):4550-6.
[49] Koetz K, et al. T cell homeostasis in patients with rheumatoid arthritis. Proc Natl Acad Sci USA 2000;97(16): 9203-8.

[50] Saoudi A, et al. The thymus contains a high frequency of cells that prevent autoimmune diabetes on transfer into prediabetic recipients. J Exp Med 1996;184(6):2393-8.

Available online at www.sciencedirect.com

$$
\text { Science@Direct }{ }^{\circledR}
$$

